\title{
Repair of the bicuspid aortic valve: A viable alternative to replacement with a bioprosthesis
}

\author{
Elena Ashikhmina, MD, PhD, ${ }^{\text {a }}$ Thoralf M. Sundt III, MD, ${ }^{a}$ Joseph A. Dearani, MD, ${ }^{a}$ \\ Heidi M. Connolly, MD, ${ }^{\mathrm{b}}$ Zhuo Li, MS, ${ }^{\mathrm{c}}$ and Hartzell V. Schaff, MD ${ }^{\mathrm{a}}$
}

Objective: We sought to compare the safety and durability of bicuspid aortic valve repair versus replacement with a bioprosthesis.

\begin{abstract}
Methods: We reviewed medical records of patients aged 18 years or older undergoing bicuspid aortic valve repair for aortic regurgitation from 1984 through 2007. We analyzed early outcomes and predictors of aortic valve replacement after initial repair. Patients with repair were compared with an age- and sex-matched cohort who had replacement with a bioprosthesis. Overall survival and survival free from reoperations were compared between groups.
\end{abstract}

Results: The mean follow-up period for 108 consecutive patients with repair was 5.1 (standard deviation, 4.1) years. The initially repaired valve was subsequently replaced in $19(18 \%)$ patients. No bicuspid aortic valve repair technique or morphologic characteristic included in univariate risk factor analysis was associated with increased probability of replacement after initial repair. The 5- and 10-year survival rates after repair were $96 \%$ and $87 \%$, respectively. Freedom from valve replacement was $96 \%, 89 \%$, and $49 \%$ at 1,5 , and 10 years after repair, respectively. A separate analysis of 81 matched patients with repair or receipt of an aortic valve bioprosthesis showed no significant difference in 10-year survival $(72 \%$ vs $79 \%, P=.13)$ or freedom from reoperation between groups ( $90 \%$ vs $98 \%$ and $72 \%$ vs $64 \%$ in 5 and 10 years, respectively; $P<.12$ ).

Conclusions: Bicuspid aortic valve repair is a viable alternative to replacement with a bioprosthesis because durability and safety are similar between both surgical management methods for aortic regurgitation. After initial repair, approximately half of the patients require aortic valve replacement within 10 years. (J Thorac Cardiovasc Surg 2010;139:1395-401)

Earn CME credits at

http://cme.ctsnetjournals.org

Bicuspid aortic valve (BAV) is a congenital anomaly with an estimated incidence in the general population of $2.5 \%$ as reported in epidemiologic reports ${ }^{1}$ and $0.9 \%$ as reported in necropsy studies. ${ }^{2}$ It is associated with aortic valve (AV) dysfunction $^{3}$ : up to $85 \%$ of patients with BAV have aortic stenosis after the fifth decade of life. Isolated aortic regurgitation (AR) is less common, affects approximately one fifth of patients with BAV, and usually manifests earlier in life than aortic stenosis. ${ }^{4}$ Because the population of patients with BAV is relatively young, the optimal surgical treatment should be durable and have a minimal effect on quality of life

\footnotetext{
From the Division of Cardiovascular Surgery, ${ }^{\text {a }}$ the Division of Cardiovascular Diseases, ${ }^{b}$ and the Division of Biomedical Statistics and Informatics, ${ }^{c}$ Mayo Clinic, Rochester, Minn.

Disclosures: None.

Received for publication July 2, 2009; revisions received Dec 15, 2009; accepted for publication Feb 13, 2010; available ahead of print April 15, 2010.

Address for reprints: Hartzell V. Schaff, MD, Division of Cardiovascular Surgery, Mayo Clinic, 200 First Street SW, Rochester, MN 55905 (E-mail: schaff@mayo. edu).

0022-5223/\$36.00

Copyright $(\mathrm{C} 2010$ by The American Association for Thoracic Surgery doi:10.1016/j.jtcvs.2010.02.035
}

and longevity. BAV repair seems to be a viable alternative to replacement techniques because it avoids complications related to artificial valves and long-term anticoagulation. During the past 2 decades, AV repair has gained more acceptance among surgeons; nevertheless, the technique is still in evolution. We present our clinic's recent experience in BAV repair for $\mathrm{AR}$, with emphasis on risks of reoperation and late cardiac death.

\section{MATERIALS AND METHODS}

After receiving study approval by the Mayo Clinic Institutional Review Board, we searched our clinic database for patients aged 18 years or older who underwent BAV repair for AR with or without concomitant supracoronary tube graft replacement of the ascending aorta for aortic dilatation from 1984 through 2007. We excluded patients with valve-sparing aortic root replacements (David and Yacoub operations), aortic stenosis, aortic dissections, prior balloon valvuloplasty, or surgical valvulotomy, and we excluded patients with iatrogenic AR acquired intraoperatively after graft replacement of the aorta or trauma to the AV.

We reviewed medical records of study patients to obtain demographic characteristics and results of echocardiographic examinations, and we reviewed surgical records for valve morphologic features and techniques of repair. Late follow-up was obtained from clinical records when available, from written correspondence with patients' physicians, or from questionnaires mailed directly to the patient and up to the latest date available.

Because some degree of annular dilatation is common in patients with regurgitant BAVs, we combined cusp repair with commissural plication to decrease the diameter of the aortic annulus. ${ }^{5}$ If the mid-ascending aorta 


\section{Abbreviations and Acronyms \\ $\mathrm{AR}=$ aortic regurgitation \\ $\mathrm{AV}=$ aortic valve \\ $\mathrm{AVR}=$ aortic valve replacement \\ $\mathrm{BAV}=$ bicuspid aortic valve \\ $\mathrm{SD}=$ standard deviation}

had a dilatation of greater than $45 \mathrm{~mm}$, it was replaced with a supracoronary tube graft.

Operations were performed with normothermic cardiopulmonary bypass, and hypothermic antegrade blood cardioplegia was used for myocardial protection. The standard technique for surgical treatment of AR in a patient with BAV has undergone evolution over time. Before 2000, most valves were repaired with triangular resection and suture repair of the median raphe. ${ }^{6}$ After 2000 and in patients with pliable cusps, prolapse was most likely corrected with plication of the median raphe without resection. Intraoperative transesophageal echocardiographic analysis was used for all study patients.

Univariate analysis was performed to identify risk factors significant for BAV replacement after initial repair. The durability of BAV repair was evaluated by estimating the freedom from aortic valve replacement (AVR). Safety of the procedure was judged with the incidence of early postoperative complications and survival. To evaluate the influence of change in operative techniques depending on the era of operation, we divided study patients into 2 subgroups (ie, those who underwent operations before 2000 and those who underwent operations in 2000 or later) and compared results of analysis of freedom from AVR between the 2 subgroups. Furthermore, we performed the same analysis, excluding patients who had AVR but whose primary indication for reoperation was not BAV repair failure.

To assess the feasibility of BAV repair compared with other conventional techniques of AR management, we matched our study cohort with patients who underwent AVR with a bioprosthesis; patients were matched by year of operation ( \pm 5 years), age, and sex. Survival and freedom from reoperation were compared between the 2 groups.

Descriptive statistics for categorical variables are reported as frequencies and percentages; continuous variables are reported as means (standard deviations [SDs]) or medians (ranges), as appropriate. Categorical variables were compared with the $\chi^{2}$ test. Continuous variables were compared with the 2-sample $t$ test or Wilcoxon rank sum test, as appropriate. The KaplanMeier method was used to draw survival curves and calculate 5- and 10-year survival statistics and freedom from AVR. Cox proportional hazards regression models were used to find the univariate predictors of time of AVR.

\section{RESULTS}

The study group contained 108 consecutive patients who met the inclusion criteria and had given consent to participate in research. Baseline characteristics of patients undergoing BAV repair are listed in Table 1. The mean age was 41 years, and most patients were men. No patient had acute endocarditis; $9(8 \%)$ patients had healed lesions and a history of treated endocarditis. The primary indication for the operation was moderately severe or severe AR in 90 $(83 \%)$ patients, and severe mitral regurgitation was associated with at least moderate AR in $9(8 \%)$ patients. Another 9 patients were sent to the surgical department because of an ascending aortic aneurysm and had concomitant repair of significant AR.

\section{Operative Techniques}

Isolated BAV repair was performed in $61(56 \%)$ patients. AV repair was combined with graft replacement in 15 patients and with reduction aortoplasty in 8 patients for dilatation of the ascending aorta (minimum, $49 \mathrm{~mm}$ ); 11 patients had concomitant mitral valve repair. Other concomitant procedures are listed in Table 1.

Surgical inspection identified a number of mechanisms of BAV regurgitation. The most common finding was scarring and retraction of the rudimentary raphe of a conjoint cusp. Other mechanisms included prolapse of both aortic cusps or of a conjoint cusp. In general, the cusps were thin and pliable, and in $83(77 \%)$ patients the cusps had no calcification.

The most common technique for BAV repair was commissural plication combined with triangular resection of the retracted rudimentary raphe. Overall, 101 patients had commissural plication. However, the operative methods changed over time. From 1984 through 1999, the retracted median raphe was excised in 24 patients and plicated in 1 patient; from 2000 through 2007, the raphe was excised in 39 patients and plicated in 19 patients.

After initial termination, cardiopulmonary bypass was resumed in $8(7 \%)$ patients: for residual AR noted with intraoperative transesophageal echocardiographic analysis in 5 patients; for mitral valve repair, tricuspid valve repair, or both in 2 patients; and for closure of an iatrogenic ventricular septal defect acquired during decalcification of the interventricular septum in 1 patient. In 2 patients a brief period of circulatory arrest (12 and 15 minutes, respectively) was used to facilitate distal anastomoses of graft repair of ascending aortic aneurysms.

Intraoperative transesophageal echocardiographic analysis was performed in $105(97 \%)$ patients; 3 patients without transesophageal echocardiographic analysis underwent operations in 1984 (2 patients) and 1986 (1 patient). None of the patients left the operating room with greater than mild residual $\mathrm{AR}$, and the mean transvalvular gradient was $16 \mathrm{~mm}$ $\mathrm{Hg}(\mathrm{SD}, 9 \mathrm{~mm} \mathrm{Hg})$.

\section{Echocardiographic Characteristics}

All patients with BAV underwent preoperative transthoracic echocardiographic analysis. The mean grade of AR in study patients was 3.2 (SD, 1.0) on a scale of 1 to 4 . For most patients, left ventricular systolic function was nor$\mathrm{mal}$; the mean of the left ventricular ejection fraction was $59 \%$ (SD, $6 \%$ ). Aortopathy was common, and the mean diameter of the proximal ascending aorta was $41 \mathrm{~mm}(\mathrm{SD}, 5$ $\mathrm{mm}$ ) in the study compared with $26 \mathrm{~mm}(\mathrm{SD}, 3 \mathrm{~mm})$ reported as a reference range by Triulzi and colleagues. ${ }^{7}$

Results of postoperative follow-up echocardiographic analyses at least 1 year after BAV repair were available in $46(43 \%)$ patients who were free from AVR (Table 2). Statistically significant decreases in the left ventricular 
TABLE 1. Baseline characteristics of patients undergoing bicuspid aortic valve repair

\begin{tabular}{|c|c|}
\hline Characteristics & $\begin{array}{c}\text { Value* } \\
(\mathbf{n}=\mathbf{1 0 8})\end{array}$ \\
\hline Age, mean (SD), y & $41(13)$ \\
\hline Male sex & $98(91)$ \\
\hline Body mass index, mean (SD), $\mathrm{kg} / \mathrm{m}^{2}$ & $27.6(5.0)$ \\
\hline \multicolumn{2}{|l|}{ Cardiac pathologic features } \\
\hline Aortic aneurysm & $23(21)$ \\
\hline Prior infectious endocarditis & $9(8)$ \\
\hline Coronary artery disease & $10(9)$ \\
\hline \multicolumn{2}{|l|}{ Prior cardiac operation } \\
\hline Coarctation repair & $10(9)$ \\
\hline \multicolumn{2}{|l|}{ New York Heart Association class } \\
\hline I & $50(46)$ \\
\hline II & $37(34)$ \\
\hline III & $19(18)$ \\
\hline IV & $2(2)$ \\
\hline Cardiopulmonary bypass time, mean (SD), min & $51(26)$ \\
\hline Crossclamping time, mean (SD), min & $38(17)$ \\
\hline \multicolumn{2}{|l|}{ Concomitant procedures } \\
\hline Graft replacement of ascending aorta & $15(14)$ \\
\hline Reduction aortoplasty & $8(7)$ \\
\hline Mitral valve repair & $11(10)$ \\
\hline Tricuspid valve repair & $2(2)$ \\
\hline Coronary artery bypass grafting & $8(7)$ \\
\hline Arterial septal defect/patent foramen ovale closure & $6(6)$ \\
\hline Ventricular septal defect & $5(5)$ \\
\hline Maze procedure & $2(2)$ \\
\hline Coarctation repair & $1(1)$ \\
\hline \multicolumn{2}{|l|}{ Morphologic features $\dagger$} \\
\hline Scarring of rudimentary raphe & $49(45)$ \\
\hline Calcification of rudimentary raphe & $16(15)$ \\
\hline Prolapse of both cusps & $36(33)$ \\
\hline \multicolumn{2}{|l|}{ Prolapse of a single cusp } \\
\hline Conjoint & $32(30)$ \\
\hline Nonconjoint & 0 \\
\hline Calcification of cusps & $9(8)$ \\
\hline Perforation of cusps & $5(5)$ \\
\hline \multicolumn{2}{|l|}{ Operative techniques } \\
\hline Commissural plication & $101(94)$ \\
\hline Triangular excision of raphe & $63(58)$ \\
\hline Plication of raphe & $20(19)$ \\
\hline Plication of free edge of conjoined cusp & $14(13)$ \\
\hline Plication of free edge of nonconjoined cusp & $18(17)$ \\
\hline Patch repair of cusp perforation & $9(8)$ \\
\hline Decalcification & $4(4)$ \\
\hline Cusp shaving & $3(3)$ \\
\hline Partial noncoronary cusp resection with plication & $3(3)$ \\
\hline
\end{tabular}

$\overline{S D \text {, Standard deviation. *Values are expressed as numbers (percentages) of patients }}$ unless specified otherwise. $\dagger$ As described by the operating surgeon.

systolic and diastolic dimensions and the left ventricular mass were observed at a mean of 4.6 years (SD, 3.5 years) after BAV repair. A decrease in AV orifice and augmentation of gradient across the $\mathrm{AV}$ were consequences of $\mathrm{AV}$ repair technique.
TABLE 2. Echocardiographic changes for patients with echocardiographic follow-up of 1 year or more after BAV repair

\begin{tabular}{|c|c|c|c|}
\hline \multirow[b]{2}{*}{ Characteristic } & \multicolumn{2}{|c|}{ Patients $(n=46)^{*}$} & \multirow[b]{2}{*}{$\begin{array}{c}P \\
\text { value }\end{array}$} \\
\hline & $\begin{array}{c}\text { Before } \\
\text { BAV repair, } \\
\text { mean (SD) }\end{array}$ & $\begin{array}{c}\text { After } \\
\text { BAV repair, } \\
\text { mean (SD) }\end{array}$ & \\
\hline LVEF, \% & $59(6)$ & $61(7)$ & .19 \\
\hline LV end-diastolic dimension, $\mathrm{mm}$ & $61(8)$ & $54(6)$ & $<.001$ \\
\hline LV end-systolic dimension, mm & $41(6)$ & $36(7)$ & $<.001$ \\
\hline LV mass, $\mathrm{g}$ & $286(70)$ & $232(63)$ & $<.001$ \\
\hline LA volume index, $\mathrm{mL} / \mathrm{m}^{2}$ & $31(14)$ & $30(9)$ & .22 \\
\hline \multicolumn{4}{|l|}{ Aortic dimensions, $\mathrm{mm}$} \\
\hline Annulus & $29(4)$ & $28(4)$ & .69 \\
\hline Valsalva sinuses & $42(6)$ & $41(6)$ & .82 \\
\hline Sinotubular junction & $35(5)$ & $34(7)$ & .35 \\
\hline Proximal ascending aorta & $42(6)$ & $38(7)$ & .36 \\
\hline Mid-ascending aorta & $41(8)$ & $37(7)$ & .37 \\
\hline Aortic arch & $31(6)$ & $30(6)$ & .79 \\
\hline Mean AV pressure gradient, $\mathrm{mm} \mathrm{Hg}$ & $10(4)$ & $17(10)$ & $<.001$ \\
\hline AV orifice (TVI), $\mathrm{cm}^{2}$ & $3.8(1.5)$ & $2.4(1.0)$ & $<.001$ \\
\hline \multicolumn{4}{|l|}{ Regurgitation grade (scale, 1-4) } \\
\hline Aortic valve & $3.1(1.0)$ & $1.2(0.8)$ & $<.001$ \\
\hline Mitral valve & $1.0(0.8)$ & $1.0(0.5)$ & .95 \\
\hline Tricuspid valve & $0.8(0.4)$ & $1.0(0.2)$ & .07 \\
\hline Pulmonary valve & $0.6(0.5)$ & $0.9(0.4)$ & .28 \\
\hline $\mathrm{RV}$ systolic pressure, $\mathrm{mm} \mathrm{Hg}$ & $34(12)$ & $31(7)$ & .62 \\
\hline
\end{tabular}

$B A V$, Bicuspid aortic valve; $S D$, standard deviation; $L V E F$, left ventricular ejection fraction; $L V$, left ventricular; $L A$, left atrium; $A V$, aortic valve; $T V I$, time velocity integral; $R V$, right ventricular. *Patients free from AVR; mean echocardiographic follow-up was 4.6 years (SD, 3.5 years; maximum, 12.7 years).

\section{Outcomes, Safety, and Durability of BAV Repair}

Among the 108 patients undergoing BAV repair, the mean follow-up period was 5.1 years (SD, 4.1 years; median, 4.1 years; range, 5 days to 22.9 years). In 2 patients no follow-up information was available beyond the initial hospitalization. Follow-up beyond the first postoperative year was available for $95(88 \%)$ patients, and $15(14 \%)$ patients had follow-up beyond 10 years postoperatively.

No early deaths occurred, and 7 (6\%) patients died late. Cause of death was unknown in 4 patients, death was cardiac related in 2 patients, and 1 patient died suddenly. The 1-, 5-, and 10 -year survival rates were $99 \%, 96 \%$, and $87 \%$, respectively, which are similar to those of an age- and sexmatched general population (Figure 1, A).

Overall, 19 patients had subsequent AVR, and cumulative risk of reoperation for AVR is shown in Figure 1, $B$. Two AVRs were performed during initial hospitalization because of severe AR identified 4 and 6 days, respectively, after initial BAV repair. One patient underwent BAV rerepair during the same hospitalization; his valve was subsequently replaced 2 years postoperatively. Failure of the repair was the primary indication for reoperation in 14 of the 19 patients. The repair failure led to severe AR in 9 patients, aortic stenosis in 2 patients, and mixed aortic stenosis and AR in 1 

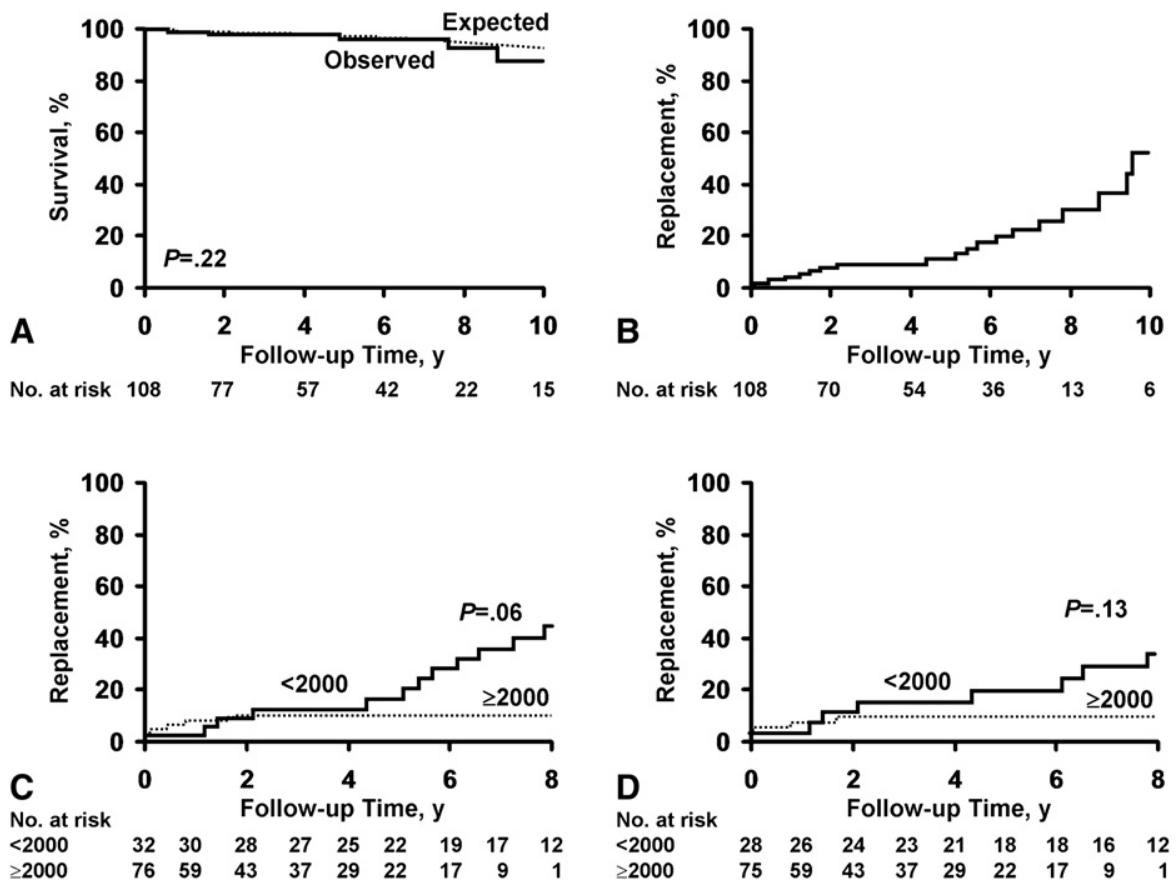

FIGURE 1. Survival and risk of aortic valve replacement (AVR) after bicuspid aortic valve (BAV) repair. A, Survival of patients with BAV repair compared with a Minnesota population of white patients of the same age and sex. B, Risk of AVR for patients with BAV repair. C, Risk of AVR for patients with BAV repair stratified by year of operation. D, Risk of AVR for patients with BAV repair stratified by year of operation after exclusion of patients who underwent reoperation for indications not related to BAV repair failure.

patient; in 2 patients the indication for late AVR was unknown. For 5 patients, late AVR was performed during a reoperation for aortic aneurysm $(\mathrm{n}=1)$, aortic dissection $(\mathrm{n}=1)$, severe angina $(\mathrm{n}=1)$, severe mitral regurgitation $(\mathrm{n}=1)$, and persistent hemolysis $(\mathrm{n}=1)$, likely because of red cell trauma from an annuloplasty ring used during prior concomitant mitral valve repair.

At reoperation for AVR, 17 patients received mechanical prostheses, and 2 patients received bioprostheses. AVR was combined with mitral valve replacement in 2 patients and with coronary artery bypass grafting in 1 patient.

To evaluate the possible effect of a surgeon's learning curve for the procedure, we stratified patients according to the era of operation. We found that there was a tendency toward a lower risk of reoperation for AVR in patients who underwent repair in 2000 or later $(P=.06$; Figure $1, C)$. To eliminate the confounding effect of late AVR during surgical intervention for another cardiac problem, we performed a similar analysis that included only the 14 patients who had late AVR caused by failure of the initial repair. The analysis showed that the tendency toward improved outcome in recent years persisted (Figure 1,D).

\section{Outcomes, Safety, and Durability of BAV Repair Versus AVR With a Bioprosthesis}

To place the outcomes of BAV repair in perspective, we matched these patients for age, sex, and year of operation to control patients who had AVR with bioprostheses. We were able to identify 81 matched pairs from our database. Most $(68 \%)$ of the group had AVR with Carpentier-Edwards pericardial bioprostheses. The mean age was 44 years (SD, 13 years) for patients with BAV repair and 45 years (SD, 13 years) for patients with AV bioprostheses $(P=.33)$. Durations of cardiopulmonary bypass and crossclamping were longer in patients with AVR than in those with BAV repair (89 minutes [SD, 44 minutes] vs 53 minutes [SD, 27 minutes] and 66 minutes [SD, 34 minutes] vs 39 minutes [SD, 18 minutes], respectively; $P<.001$ ).

The length of available follow-up was similar among patients with BAV repairs and patients with AVR (4.2 years [SD, 3.2 years] vs 4.2 years [SD, 3.5 years]). Overall survival was similar for patients undergoing valve repair and those undergoing valve replacement (Figure 2, A). Risk of reoperation was also similar between the 2 groups $(P=.12$; Figure $2, B)$. Among matched patients with BAV repairs, 4 underwent reoperation because of causes unrelated to failure of BAV repair. After excluding these patients (and their matching cohort with bioprostheses), we again compared the risk of reoperation between the 2 groups $(\mathrm{n}=77)$ and found no statistical difference in freedom from reoperation $(P=.66$; Figure 2, $C)$.

Early postoperative complications were more frequent among patients with AVR. Overall, 37 (46\%) patients with aortic bioprostheses had complicated postoperative recovery; in the BAV repair group $24(30 \%)$ patients had some complication after surgical intervention $(P=.04)$. 

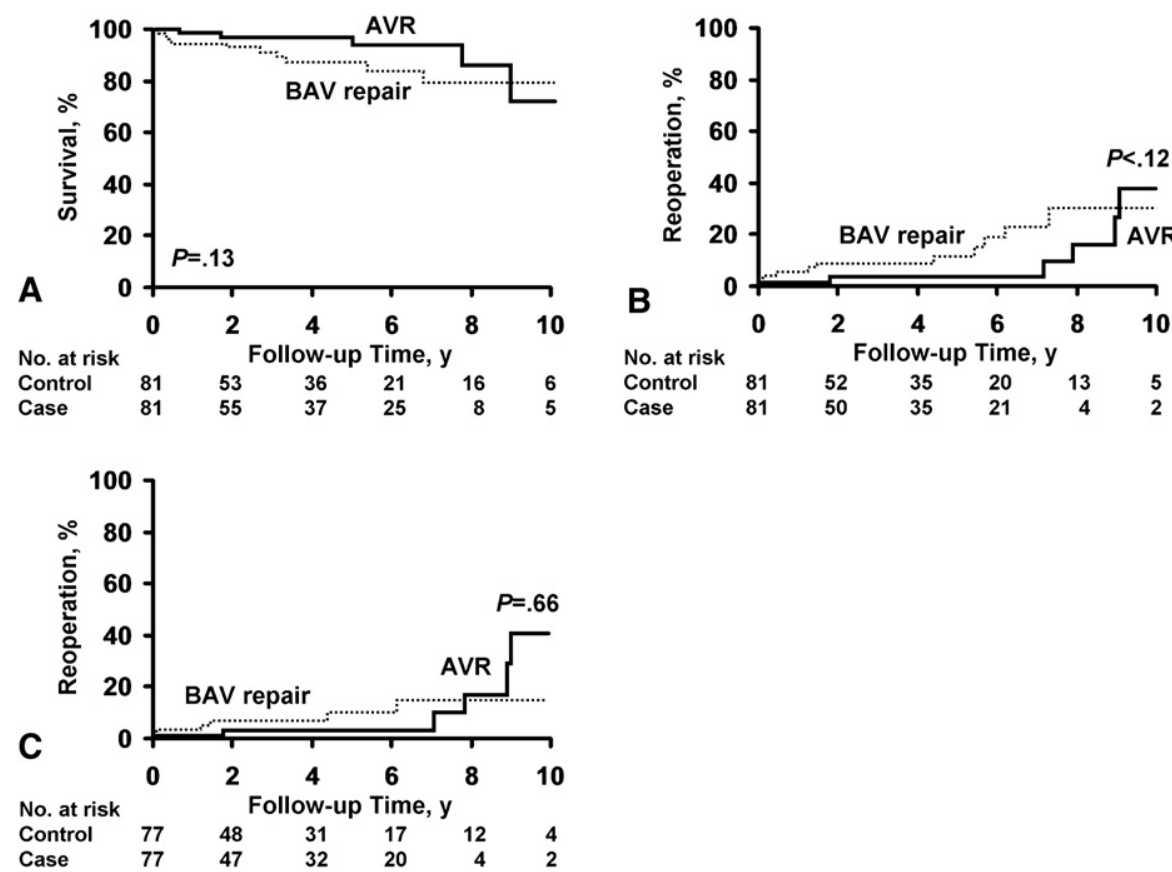

FIGURE 2. Survival and risk of reoperation in matched groups after bicuspid aortic valve $(B A V)$ repair and aortic valve replacement $(A V R)$ with a bioprosthesis. A, Survival of patients after BAV repair matched to patients who underwent AVR with a bioprosthesis. B, Risk of reoperation in matched patients who underwent BAV repair or AVR with a bioprosthesis. C, Risk of reoperation in matched patients who underwent BAV repair or AVR with a bioprosthesis after exclusion of patients and their matched pairs who underwent reoperation for indications not related to BAV repair failure.

The major difference between the 2 groups was the requirement of prolonged mechanical ventilation in $6(7 \%)$ patients with AVR; no patient with BAV repair received mechanical ventilation for more than 24 hours $(P=.03)$. No statistically significant difference was found in the incidence of any other early postoperative complications, such as sternal wound infection $(P=.99)$, renal failure $(P=.99)$, onset of atrial fibrillation $(P=.13)$, pneumonia $(P=.12)$, sepsis $(P=.50)$, or re-exploration for bleeding $(P=.99)$. During late follow-up, endocarditis was reported in 4 patients who had AVR, and stroke occurred in 3 patients; no episode of endocarditis or stroke occurred in patients who had BAV repair.

\section{Risk Factors of BAV Repair Failure}

Several candidate variables were entered into the univariate analysis to discriminate potential risk factors related to time of AVR: age at original BAV repair; sex; body mass index; year of operation; era of operation (before 2000 or after 2000); left ventricular function; concomitant cardiac pathologic factors (eg, coarctation); AV morphologic characteristics as described by the operating surgeon, including calcification; AV repair techniques; concomitant procedures; and the mean AV gradient at recent follow-up transthoracic echocardiographic analysis. None of these variables were statistically significant in predicting the risk of AVR after BAV repair as it related to time of replacement.

\section{DISCUSSION}

AV repair has several potential advantages over AVR for younger patients with AR caused by BAV. Although valve repair often includes commissural plication sutures, which can narrow the annulus, preservation of the dynamics of the native valve annulus and tissue might have hemodynamic benefits over a rigid prosthetic valve stent. Also, risks of thromboembolic events, anticoagulation-related complications, and endocarditis appear to be reduced after valve repair $^{8}$ compared with after replacement. However, as outlined in the 2006 American College of Cardiology/American Heart Association Guidelines for the Management of $\mathrm{Pa}$ tients With Valvular Heart Disease, ${ }^{9}$ AV repair involves a "lack of uniform applicability [and] lack of widespread experience with surgical techniques." Furthermore, there are no clear indications on when repair should be attempted, and data showing its safety and durability are limited. Most publications in the medical literature report either a relatively short follow-up period (2-4 years) $)^{10-12}$ or a small number of patients with a longer follow-up period. ${ }^{13,14}$

Also, assessment of results of AV repair is confounded because most reports describe mixed groups of patients, including those with tricuspid and bicuspid valve repairs, as well as valve repair performed during procedures for aortic root reconstruction. In a study of 54 patients, Rao and associates $^{13}$ reported survival rates of $98 \%$ and $74 \%$, respectively, at 5 and 10 years after repair of AR for patients 
TABLE 3. Freedom from reoperation for patients undergoing bicuspid aortic valve repair

\begin{tabular}{|c|c|c|c|c|c|c|c|c|}
\hline \multirow[b]{2}{*}{ Study report } & \multirow[b]{2}{*}{ Follow-up, mean (SD), y } & \multirow[b]{2}{*}{ Years of study } & \multirow[b]{2}{*}{ No. of patients } & \multirow[b]{2}{*}{ Age, mean (SD), y } & \multicolumn{4}{|c|}{$\begin{array}{l}\text { Patients free from } \\
\text { reoperation, } \% *\end{array}$} \\
\hline & & & & & $1 \mathbf{y}$ & $5 y$ & $7-8 y$ & $10 \mathrm{y}$ \\
\hline Alsoufi and coworkers ${ }^{16}$ & $3.5(2.7)$ & 1993-2005 & 71 & $42(13)$ & 97 & 90 & 82 & NA \\
\hline Casselman and coworkers ${ }^{17}$ & $5.1(2.4)$ & 1988-1997 & 94 & $38(10)$ & 95 & 87 & 84 & NA \\
\hline Davierwala and coworkers ${ }^{11}$ & $2.6(2.1)$ & 1993-2002 & 44 & $39(12)$ & 95 & 91 & NA & NA \\
\hline Fraser and coworkers ${ }^{10}$ & $2.0(1.3)$ & $1988-1993$ & 72 & $39(11)$ & 94 & NA & NA & NA \\
\hline Kin and coworkers ${ }^{18}$ & $3.3(1.9)$ & 1993-2000 & 19 & $42(17)$ & 87 & 76 & NA & NA \\
\hline Present study & $5.1(4.1)$ & 1984-2007 & 108 & $41(13)$ & 96 & 89 & 75 & 49 \\
\hline
\end{tabular}

$S D$, Standard deviation; $N A$, not applicable. *According to mean years of follow-up after bicuspid aortic valve repair.

with congenital heart disease. Of these patients, $43 \%$ had BAV. de Kerchove and coworkers ${ }^{8}$ reported a $99 \%$ 4-year survival rate for patients with AV repair, of whom $53 \%$ had BAV. In an earlier study from our institution in a mixed group of patients undergoing AV repairs, of whom $34 \%$ had BAV, freedom from cardiac death was $96 \%$ at 5 years. ${ }^{7}$

In contrast to these earlier reports, the present investigation focused on outcomes of a homogenous group of patients with regurgitation of a BAV. After valve repair, patient survival rates at 1,5 , and 10 years postoperatively were $99 \%$, $96 \%$, and $87 \%$, respectively, which are similar to those of the general US population. We also observed no significant difference in the survival of patients undergoing BAV repair compared with that seen in matched patients undergoing AVR with a bioprosthesis $(P=.13)$, again supporting the safety of this strategy for patients with severe regurgitation caused by BAV.

The primary concerns of AV repair are durability and risk of surgical reintervention. In a series of 173 patients undergoing BAV repair, Schafers and associates ${ }^{15}$ reported a 5-year rate of $94 \%$ for freedom from any reoperation after isolated BAV repair, 97\% after repair and aortic root reconstruction, and $53 \%$ after repair combined with replacement of the ascending aorta; the rate of freedom from AVR was $98 \%, 99 \%$, and $80 \%$, respectively. Table $3^{10,11,16-18}$ summarizes results of other reports that provide detailed information on freedom of reoperation after BAV repair. Few of these studies had a follow-up beyond 5 years.

The American College of Cardiology/American Heart Association guidelines report that by 10 years of follow-up, the overall rate of AVR after prior AV repair is approximately $15 \% .{ }^{9}$ The overall risk of reoperation in our study was $18 \%$, but this percentage includes AVR performed during reoperation for other indications. The overall risk of AVR for failure of initial repair was $16 \%$. Indeed, the cumulative risk of reoperation for failure of initial repair was seen to increase after 5 years, as did the risk of reoperation in our matched patients with bioprostheses. It appears that late results of repair of BAV have improved in the most recent decade (Figure 2, C), likely because of improved patient selection.

Although our statistical analysis did not identify preoperative hemodynamic and morphologic features that predicted a need for late reoperation, experience has shown that marked thickening of cusps and calcification are unfavorable characteristics. We agree with the systematic approach suggested by Pettersson and colleagues ${ }^{5}$ based on the echocardiographic evaluation. In their study conjoint cusp tissue restriction and deficiency, combined with cusp thickening and cusp calcification, were unfavorable features for reparability. We believe that these characteristics also influence late durability when such valves are repaired. Important, too, are the criteria for successful repair, which include a grade of AR of 1 or less and a mean AV gradient of less than $15 \mathrm{~mm} \mathrm{Hg}$ or a peak AV gradient of less than $30 \mathrm{~mm} \mathrm{Hg} .^{5}$

Nevertheless, the cause of deterioration of BAV repair continues to be unclear. Several studies have investigated risk factors for failure of BAV repair. ${ }^{8,17,19}$ Casselman and coworkers ${ }^{17}$ described left ventricular dysfunction as a predictor of immediate, persistent AR of more than +1 after BAV repair, but they did not identify risk factors for late regurgitation. Nash and colleagues ${ }^{19}$ reported echocardiographic parameters associated with increased likelihood of successful BAV repair, and these parameters included an eccentric jet of AR, absence of cuspal or commissural thickening, and lack of cusp calcification. Multivariate analysis by de Kerchove and coworkers ${ }^{8}$ suggested that methods of repair of the prolapsed cusp and increased left ventricular end-diastolic diameter were predictors of BAV repair failure. In our study none of the variables that potentially could increase the risk of AVR after BAV repair turned out to be statistically significant. It is possible that some other factors that were not tested but were associated with repair failure or with the numbers of patients and events (replacements), as well as the duration of follow-up, were not sufficient to identify risk factors.

Debates are ongoing over the most reliable technique of $\mathrm{AV}$ repair. The change of surgical technique from triangular resection to tissue-sparing plication of the midportion of the conjoint cusp is expected to improve repair durability. However, in the series reported by Aicher and associates, ${ }^{14}$ triangular resection of a portion of the prolapsing cusp did not compromise midterm durability of repair. Our current preference for plication rather than cusp resection evolved with increasing experience. We initially followed the 
methods described by Cosgrove and colleagues, ${ }^{20}$ which involved excision of the raphe of the prolapsing cusp, and this method is still useful when there is marked thickening of this area. However, when the conjoint cusp is very pliable and thickness is near normal, plication to shorten the free edge is done easily and avoids risk of sutures pulling through the thinner areas of the midcusp. Although not statistically significant, the rate of reoperation after BAV repair for patients who underwent operations after 2000 was lower than for patients undergoing operations in the previous decade. This lower rate likely reflects improved patient selection, as well as use of the plication method.

An important finding in the present study was the comparability of risk of reoperation for patients undergoing BAV repair versus AVR with a bioprosthesis. As shown in Figure 2, $B$ and $C$, the cumulative risk of reoperation for patients with a bioprosthesis appears to increase sharply after 8 years, although our follow-up beyond this time is limited. Goland and associates ${ }^{21}$ reported that the risk of reoperation 10 years after AVR with a bioprosthesis reached $30 \%$ to $50 \%$ depending on the decade when the initial operation was performed. In addition to the relatively high rate of reintervention, patients undergoing AVR with a bioprosthesis are still at risk for prosthetic valve-related complications, particularly prosthetic valve endocarditis and thromboembolism, and the risks of these complications were notably low (ie, no events) among patients undergoing valve repair.

\section{Study Limitations}

The mean age of the study patients was 41 years (SD, 13 years), and our reported results do not assess the safety and durability of BAV repair in a younger population. All patients in the study had preserved left ventricular ejection fraction ( $\geq 45 \%)$, and thus no conclusion can be made about the feasibility of BAV repair in patients with impaired myocardial performance. Also, the follow-up period is relatively short; with additional time, repaired valves might have calcification and stenosis. As previously reported, we matched control patients with bioprostheses for only 81 of the 108 patients in the overall study. Nevertheless, our data provide a longer follow-up period on repaired BAV than prior reports. Finally, the end point of our statistical analysis was reoperation but not the grade of $\mathrm{AR}$, and thus the incidence of severe AR (eg, repair failure) might be underestimated.

\section{CONCLUSION}

BAV repair is a safe and durable technique for AR management. It is a viable alternative to AVR with a bioprosthesis because a comparison of these 2 therapeutic approaches shows no advantage in survival and durability.

\section{References}

1. Stefani L, Galanti G, Toncelli L, Manetti P, Vono MC, Rizzo M, et al. Bicuspid aortic valve in competitive athletes. Br J Sports Med. 2008;42:31-5.

2. Roberts WC. The congenitally bicuspid aortic valve: a study of 85 autopsy cases. Am J Cardiol. 1970;26:72-83.

3. Ward C. Clinical significance of the bicuspid aortic valve. Heart. 2000;83 $81-5$.

4. Sabet HY, Edwards WD, Tazelaar HD, Daly RC. Congenitally bicuspid aortic valves: a surgical pathology study of 542 cases (1991 through 1996) and a literature review of 2,715 additional cases. Mayo Clin Proc. 1999;74:14-26.

5. Pettersson GB, Crucean AC, Savage R, Halley CM, Grimm RA, Svensson LG, et al. Toward predictable repair of regurgitant aortic valves: a systematic morphology-directed approach to bicommissural repair. J Am Coll Cardiol. 2008;52:40-9.

6. Minakata K, Schaff HV, Zehr KJ, Dearani JA, Daly RC, Orszulak TA, et al. Is repair of aortic valve regurgitation a safe alternative to valve replacement? J Thorac Cardiovasc Surg. 2004;127:645-53.

7. Triulzi M, Gillam LD, Gentile F, Newell JB, Weyman AE. Normal adult crosssectional echocardiographic values: linear dimensions and chamber areas. Echocardiography. 1984;1:403-26.

8. de Kerchove L, Glineur D, Poncelet A, Boodhwani M, Rubay J, Dhoore W, et al Repair of aortic leaflet prolapse: a ten-year experience. Eur J Cardiothorac Surg. 2008;34:785-91.

9. Bonow RO, Carabello BA, Chatterjee K, de Leon AC Jr, Faxon DP, Freed MD, et al, American College of Cardiology, American Heart Association Task Force on Practice Guidelines (Writing Committee to revise the 1998 guidelines for the management of patients with valvular heart disease), Society of Cardiovascular Anesthesiologists. ACC/AHA 2006 guidelines for the management of patients with valvular heart disease: a report of the American College of Cardiology/ American Heart Association Task Force on Practice Guidelines (Writing Committee to Revise the 1998 guidelines for the management of patients with valvular heart disease) developed in collaboration with the Society of Cardiovascular Anesthesiologists endorsed by the Society for Cardiovascular Angiography and Interventions and the Society of Thoracic Surgeons. J Am Coll Cardiol. 2006;48: e1-148 [published erratum in J Am Coll Cardiol. 2007;49:1014].

10. Fraser CD Jr, Wang N, Mee RB, Lytle BW, McCarthy PM, Sapp SK, et al. Repair of insufficient bicuspid aortic valves. Ann Thorac Surg. 1994;58:386-90.

11. Davierwala PM, David TE, Armstrong S, Ivanov J. Aortic valve repair versus replacement in bicuspid aortic valve disease. J Heart Valve Dis. 2003;12:679-86.

12. El Khoury G, Vanoverschelde JL, Glineur D, Pierard F, Verhelst RR, Rubay J, et al. Repair of bicuspid aortic valves in patients with aortic regurgitation. Circulation. 2006;114(suppl):I610-6.

13. Rao V, Van Arsdell GS, David TE, Azakie A, Williams WG. Aortic valve repair for adult congenital heart disease: a 22-year experience. Circulation. 2000; 102(suppl 3):III40-3.

14. Aicher D, Langer F, Adam O, Tscholl D, Lausberg H, Schafers HJ. Cusp repair in aortic valve reconstruction: does the technique affect stability? $J$ Thorac Cardiovasc Surg. 2007;134:1533-8.

15. Schafers HJ, Aicher D, Langer F, Lausberg HF. Preservation of the bicuspid aortic valve. Ann Thorac Surg. 2007;83(suppl):S740-5.

16. Alsoufi B, Borger MA, Armstrong S, Maganti M, David TE. Results of valve preservation and repair for bicuspid aortic valve insufficiency. $J$ Heart Valve Dis. 2005; $14: 752-8$.

17. Casselman FP, Gillinov AM, Akhrass R, Kasirajan V, Blackstone EH, Cosgrove DM. Intermediate-term durability of bicuspid aortic valve repair for prolapsing leaflet. Eur J Cardiothorac Surg. 1999;15:302-8.

18. Kin H, Izumoto H, Nakajima T, Kawase T, Kamata J, Ishihara K, et al. Midterm results of conservative repair of the incompetent bicuspid aortic valve. J Cardiovasc Surg (Torino). 2003;44:19-23.

19. Nash PJ, Vitvitsky E, Li J, Cosgrove DM 3rd, Pettersson G, Grimm RA. Feasibility of valve repair for regurgitant bicuspid aortic valves: an echocardiographic study. Ann Thorac Surg. 2005;79:1473-9.

20. Cosgrove DM, Rosenkranz ER, Hendren WG, Bartlett JC, Stewart WJ. Valvuloplasty for aortic insufficiency. J Thorac Cardiovasc Surg. 1991;102:571-6.

21. Goland S, Czer LS, De Robertis MA, Mirocha J, Kass RM, Fontana GP, et al. Risk factors associated with reoperation and mortality in 252 patients after aortic valve replacement for congenitally bicuspid aortic valve disease. Ann Thorac Surg. 2007;83:931-7. 